\title{
Plant Leaf Disease Detection Using SVM Technique
}

\author{
${ }^{1}$ Naveen Kishore Gattim, ${ }^{2}$ Subba Reddy Pallerla, ${ }^{3}$ Polaiah Bojja, ${ }^{4}$ Tallem Pavan kumar Reddy, ${ }^{5}$ Vempati \\ Nikhil Chowdary, ${ }^{6} \mathrm{~V}$ Dhiraj, ${ }^{7}$ Sk Hasane Ahammad \\ 1,2,3,4,5,6,7 Koneru Lakshmaiah Education Foundation, India, Email: ahammad@kluniversity.in
}

\begin{abstract}
Plant disease are most common in India. Plant diseases are normally occurring due to insects. If not predict under certain time, we may chance to lose efficiency of Crops. In this paper we are helping to farmers to know and analysis the diseases. We work on an SVM for recognition and categorizing of four-leaf diseases i.e. Alternaria Alternata, Anthracnose, Bacterial Blight, Carpospora are the diseases, we worked out and we provided effective solutions to the farmers.
\end{abstract}

Key words: Standard Deviation, Entropy, Variance, RMS, SVM, K-Means, Mean.

\section{INTRODUCTION}

India is mostly dependent on agriculture. Most of the revenue will generate from Agriculture. Eighty Percentage of population in India depends on Agriculture. In this paper, we want to provide a better solution for farmers by avoiding these kinds of diseases. Suppose by seeing the leaf the farmer may not predict which type of disease it is. Assume certain type of disease and use pesticides based upon the diseases if the farmer prediction is false, then the actual disease will not be going to cure, then the farmer doesn't get better results. And wasted money due to false assumptions. So, we want to provide a effective solutions by using SVM and K-Means algorithm written in a MATLAB code which will provides the automatic disease prediction, and also estimate the effected leaf area.

\section{LITERATURE SURVEY}

Sonal Patel and Arun kumar had followed the techniques $\mathrm{K}$-means and image processing for identification of leaf diseases. By using K-means they segmented the leaves according to diseases of plants and image processing is used to extract the colors which is useful for segmentation. They also used artificial neural networks for texture analysis [2].
Shima Ramesh, Ramachandra and Vinod had developed the process by using machine learning algorithm which is random forest algorithm. For implementing this method, they created two datasets (healthy dataset and disease dataset). For features extraction they used HOG (Histogram of Oriented Gradient [3].

Shivani and Dhanashri had proposed some other techniques to identify diseases in leaves. They extracted images of leaves by using Agrobot. To classify diseased leaves, they choose Neural Network Classifier and for feature extraction they used Color Co-Occurrence [4].

Bharat Mishra, Mamta Lambert, Sumit Nema and Swapnil Nema had classified the diseased leaves by using different image processing techniques. In this project they developed algorithm by using histogram equalization, unsharp mask filtering, linear contrast adjustment and decorrelation stretch [5].

Anuradha Badage had developed a machine learning system which consists of two stages. In one stage they train the images of healthy and diseased leaves and extract the threshold value for comparing new images. In second stage they compare the RGB values of image with threshold and identifies the diseases of leaf by using histogram analysis [6].

Jyoti Shirahatti, Rutuja Patil and Pooja Akulwar had made a survey on machine learning techniques how they work in identification of leaf diseases. In their survey they have made research on Decision tree learning, Association Rule learning, Ann, SVM and genetic algorithm. They also mentioned about advantages and disadvantages of all these machine learning techniques in leaf disease detection [7].

Prajwala TM, Alla Pranathi and Kandiraju Sai Ashritha had done research on leaf disease detection of tomato plant. In their work they developed an algorithm to identify disease by using convolution neural networks. In this project first they undergo with pre-processing to reduce the noise for better results next they will classify the leaves by using convolution neural network [8-20]. 


\section{PROPOSED METHODOLOGY}

The disease prediction had to be performed in a sequential manner. To get more accuracy steps in detection of disease.

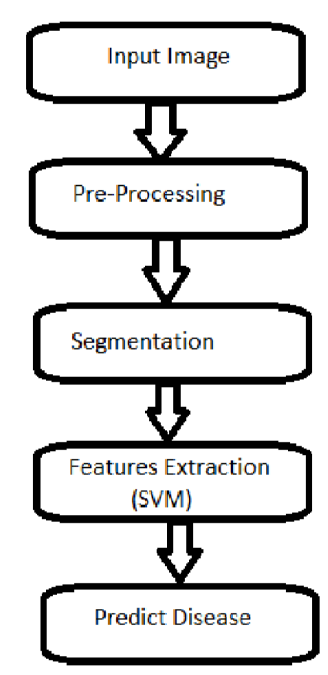

Figure 1: Basic Steps for plant disease detection and classification

\section{A. Image Extraction}

Image Extraction is a main step which is taken from the database. We take from the database from plant village where we have thousands of pictures of different plants with affected with different diseases and healthy leafs. From that we take one image and pre-processed further.

\section{B. Pre-processing of image}

The image is taken from the database and remove the unwanted noise and highlight the diseased part of the leaf. First the image has resized into 250x 250 pixels. To remove the noise previously, we used Mean filter, but now we are using Median filter to give more accurate results when compares to mean filter. And it prevents edges while removal of unwanted noise. And also we increase the intensity level of the pixels of the leaf image for further classification.

\section{K-means Segmentation}

Segmentation is one of the critical steps in leaf disease prediction, which is used for the knowing the affected a region of the leaf images. In this segmentation regions are separated based upon the pixel values. For the partition of the image we apply K-Means algorithm for the given image

\section{Feature extraction}

In this step, we done after segmentation. The segmented image further extracts the features like Mean, Standard Deviation, Entropy, RMS and Variance. This feature is calculated in MATLAB through pre-defined codes. Those are the parameters for SVM Classifier.

\section{E. Classification}

In this we classify various disease of segmented image By training the svm system with mean, standard deviation, rms, entropy, variance. Based upon range of the above parameters value system will train algorithm with the huge number of data that we are collected. In training the system allocates certain ranges for different parameters.

If training part is done, we move on to the testing part here again all the steps were performed and calculated the different parameters then we look for parameters range matching of the disease then based upon the matching we predict the disease. In certain way we train the system to perform the image classification

Implementation technique:

K-means clustering:

Here k-means clustering is used to separate or identify or grouping of nearly same pixel value into one group.

So that we can highlight the disease part and also healthy part of the leaf.

:

1. Pick the mid value of cluster, starting value or end value or any mid level value.

2. Take this as centroid of the image

3. calculate the minimum distance between centroid and all pixel values in the image

3. do the step repeatedly on cluster centers on means all the pixels in the cluster. Repeat the steps for future more time to attain the good clustering and to make the system effective.

$J=\sum_{i=1}^{m} \sum_{k=1}^{K} \omega_{i k}\left\|x^{i}-\mu_{k}\right\|^{2}$

Svm:

The svm classifier is used to classify the diseases

Step1: initial we train calculate the mean, standard deviation, rms, variance and entropy values of image

Step2: we train with those values of the diseased leaf.

Step3: now we test the data set of leaf images.

$$
s-\frac{1}{2} w^{\mathrm{r}} w+c \sum_{i=1}^{N} \mathrm{~s}_{\mathrm{i}}
$$

\section{QUALITATIVE ANALYSIS}

1) Mean:

Mean is nothing but sum of all pixel values by total number of pixel. This is used to remove the noise or unwanted data.

$f(x, y)-\frac{1}{m n} \sum_{r, c \in w} g(r, r)$

$\mathrm{F}(\mathrm{x}, \mathrm{y})$ is restored image 
2) Standard Deviation:

For the sharping of edges, we use the standard deviation which obtained from the mean

$$
f(x, y)=\sqrt{\frac{1}{m n-1} \sum_{\langle(r, c) \in w}\left(g(r, c)-\frac{1}{m n-1} \sum_{(r, c) \epsilon w} g(r, c)\right)^{2}}
$$

\section{3) Entropy:}

Entropy value is used to differentiate the pixel levels based upon that we compare the image in detailed manner

$H=-\sum_{k} p_{k} \log _{2}\left(p_{k}\right)$

4) Variance:

Variance tells about the difference between the square root of actual value and expected value

\section{Variance $=\sqrt{\text { Standard Deviation }}$}

5) Root Mean Square:

It is also one of key parameter while deciding the disease. When plant effected with more than one disease it plays a Crucial role

$$
\text { RMS }=\sqrt{\sum_{j=1}^{n} \frac{1}{n} a^{2}}
$$

Table 1: Parameters of Leaves

\begin{tabular}{|l|l|l|l|l|l|}
\hline Disease & $\begin{array}{l}\text { mea } \\
\mathrm{n}\end{array}$ & $\begin{array}{l}\text { Standard } \\
\text { Deviatio } \\
\mathrm{n}\end{array}$ & $\begin{array}{l}\text { Entrop } \\
\mathrm{y}\end{array}$ & RMS & $\begin{array}{l}\text { Vari } \\
\text { ance } \\
(\mathrm{x} 10 \\
00)\end{array}$ \\
\hline $\begin{array}{l}\text { Alternaria } \\
\text { Alternata }\end{array}$ & $\begin{array}{l}40-1 \\
30\end{array}$ & $60-110$ & $1.5-5$ & $\begin{array}{l}3.5-1 . \\
4\end{array}$ & $2-14$ \\
\hline $\begin{array}{l}\text { Anthracn } \\
\text { ose }\end{array}$ & $\begin{array}{l}15-4 \\
0\end{array}$ & $40-60$ & $1.2-4$ & $\begin{array}{l}4.0-9 . \\
7\end{array}$ & $2-3.9$ \\
\hline $\begin{array}{l}\text { Bacterial } \\
\text { Blight }\end{array}$ & $\begin{array}{l}20-3 \\
0\end{array}$ & $50-60$ & $1.3-3$ & $\begin{array}{l}1.68- \\
3\end{array}$ & $\begin{array}{l}2.5-3 \\
.5\end{array}$ \\
\hline $\begin{array}{l}\text { Cercospor } \\
\text { a Leaf } \\
\text { Spot }\end{array}$ & $\begin{array}{l}32-5 \\
0\end{array}$ & $60-80$ & $1.75-5$ & $7-10$ & $\begin{array}{l}3.5-5 \\
.3\end{array}$ \\
\hline $\begin{array}{l}\text { Healthy } \\
\text { Leaf }\end{array}$ & $35-5$ & $55-70$ & $42-5$ & $\begin{array}{l}10.06 \\
-12.6\end{array}$ & $\begin{array}{l}2.5-3 \\
.1\end{array}$ \\
\hline
\end{tabular}

\section{RESULTS}

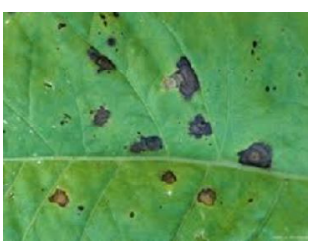

Figure: a

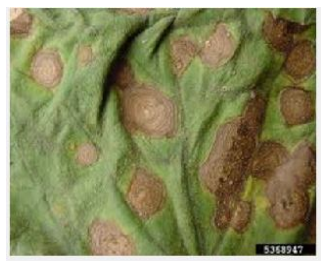

Figure: c

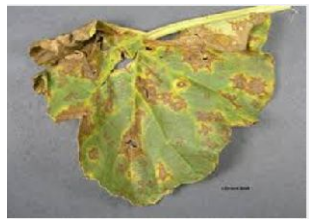

Figure: e

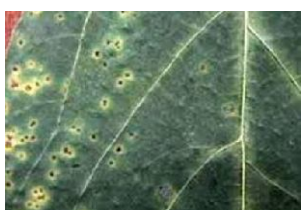

Figure: $\mathrm{g}$

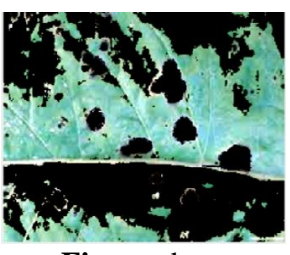

Figure: b

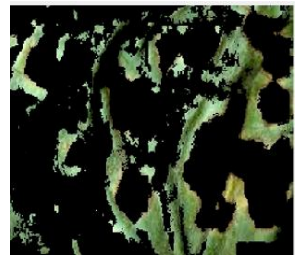

Figure: $d$

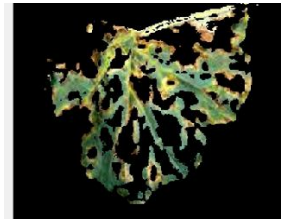

Figure: $\mathrm{f}$

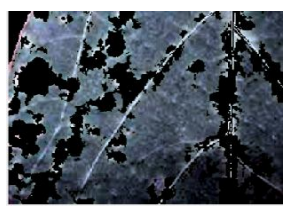

Figure: $\mathrm{h}$
In figures Fig-a,Fig-c,Fig-e,Fig-g the spotted regions are affected with some disease which can't be identified normally. After segmentation Fig-b, Fig-d, Fig-f, Fig-h are the image which is used to identify the affected area of a disease the black region in Fig-b, Fig-d, Fig-f, Fig-h will be noticed as diseased area of disease known as Alternaria Alternata, Anthransoce, Bacterial Blight, Cercospora

\section{CONCLUSION}

In this paper we are helped farmers to know and analysis the diseases. We worked on a SVM for recognition and categorizing of four leaf diseases i.e. Alternaria Alternata, Anthracnose, Bacterial Blight, Carpospora are the diseases, we worked out and we provided effective solutions to the.

\section{REFERENCES}

1. Singh Malti K and Chetia S, Diseased Leaf detection using K-Means and Texture features. International Journal of Recent Scientific Research Vol. 9, Issue, 2(I), pp. 24427-24429, February 2018. 
2. Sonal Patel P and Arun Kumar D, Automatic Detection of Plant Leaf Disease Using K-Means Clustering and segmentation. International Journal of Scientific Research Engineering \& Technology (IJSRET), ISSN 2278 - 0882 Volume 6, Issue 7, July 2017.

3. Shima Ramesh, Ramachandra and Vinod, Plant Disease Detection Using Machine Learning. International Conference on Design Innovations for 3Cs Compute Communicate Control, 2018.

4. Shivani K Tichkule, Dhanashri H Gawali, Plant Diseases Detection Using Image Processing Techniques. Online International Conference on Green Engineering and Technologies (IC-GET), 2016. https://doi.org/10.1109/GET.2016.7916653

5. Bharat Mishra, Mamta Lambert, Sumit Nema and Swapnil Nema, Recent Technologies of Leaf Disease Detection using Image Processing Approach. International Conference on Innovations in Information, Embedded and Communication Systems (ICIIECS), 2017.

6. Anuradha Badage, Crop Disease Detection using Machine Learning: Indian Agriculture. International Research Journal of Engineering and Technology (IRJET), 2018.

7. Joyti Shirahatti, Rutuja Patil and Pooja Akulwar, A Survey Paper on Plant Disease Identification using Machine Learning Approach. Proceedings of the International Conference on Communication and Electronics Systems (ICCES), 2018.

https://doi.org/10.1109/CESYS.2018.8723881

8. Prajwala TM, Alla Pranathi and Kandiraju Sai Ashritha, Tomato Leaf Disease Detection using Convolution Neural Networks. Proceedings of 2018 Eleventh International Conference on Contemporary Computing (IC3), August 2018.

9. Pooja V, Rahul Das and Kanchana V, Identification of Plant Leaf Disease using Image Processing Techniques. IEEE International Conference on Technological Innovations in ICT For Agriculture and Rural Development, 2017. https://doi.org/10.1109/TIAR.2017.8273700

10. Arti N. Rathod, Bhavesh Tanawal and Vatsal Shah, Image Processing Techniques for Detection of Leaf Disease, International Journal of Advanced Research in Computer Science and Software Engineering, November 2013.

11. Ashish Nage and V.R. Raut, Detection and Identification of Plant Leaf Diseases based on Python. International Research Journal of Engineering and Technology (IRJET), May 2019.

12. Srdjan Sladojevic, Marko Arsenovic and Andras Anderla, Deep Neural Networks based Recognition of Plant Diseases by Leaf Image Classification. Hindawi Publishing Corporation Computational Intelligence and Neuroscience, 2016. https://doi.org/10.1155/2016/3289801
13. S. Veni, P.M. Vishnu Priya, G.M Aishwarya Mala, Aswini Kayar, R. Anusha, Computer Aided for Detection of Brinjal Leaf Diseases using Thermal and Visible Light Images, Journal of Theoretical and Applied Information Technology, 2017.

14. Hashim, Haron, Osman and Al Junid, Classification of Rubber Tree Leaf Disease Using Spectrometer. Fourth Asia International Conference of Mathematical/ Analytical Modelling and Computer Simulation, 2010.

15. Naveen Kishore Gattim, Dr. V. Rajesh, Multimodal Medical Image Fusion under Redundant Transforms. International Review on Computers and Software, Vol. 10, No. 3, March 2015, pp. 241-248. https://doi.org/10.15866/irecos.v10i3.4888

16. Naveen Kishore Gattim, Dr. V. Rajesh, Rotation and Scale Invariant Feature Extraction for MRI Brain Images. Journal of Theoretical and Applied Information Technology, Vol.70 No.1, Dec 2014, Page 62-67.

17. Naveen Kishore Gattim, V Rajesh, et.al., Multimodal Image Fusion Using Curvelet and Genetic Algorithm. Journal of Scientific and Industrial Research (JSIR), ISSN 0975-1084 Vol 76, Nov 17, pp. 694-696.

18. Ahammad, SK Hasane, V. Rajesh, and MD Zia Ur Rahman. \& quot; Fast and Accurate Feature Extraction-Based Segmentation Framework for Spinal Cord Injury Severity Classification. \& quot; IEEE Access 7 (2019): 46092-46103. https://doi.org/10.1109/ACCESS.2019.2909583

19. Ahammad, S. H., Rajesh, V., Saikumar, K., Jalakam, S., \& Kumar, G. N. S. (2019). Statistical analysis of spinal cord injury severity detection on high dimensional MRI data. International Journal of Electrical and Computer Engineering, 9(5), 3457-3464.

20. Hasane Ahammad, S., Rajesh, V., Hanumatsai, N., Venumadhav, A., Sasank, N. S. S., Bhargav Gupta, K. K., \& Inithiyaz, S. (2019). MRI image training and finding acute spine injury with the help of hemorrhagic and non hemorrhagic rope wounds method. Indian Journal of Public Health Research and Development, 10(7), 404-408. https://doi.org/10.5958/0976-5506.2019.01603.6 